\title{
Letter-to-the-editor on Yang et al. Surg Endosc 2008;22:1620-1624
}

\author{
Peter W. Plaisier · René L. van der Hul
}

Published online: 24 January 2009

(C) Springer Science+Business Media, LLC 2009

\section{Dear Sir,}

We read with great interest the article by Yang et al. on biochemical predictors of common bile duct (CBD) stones [1], not least because we wrote a review article on the very same subject 15 years ago [2].

Obviously, the authors are to be congratulated on the enormous amount of data they have gathered on this interesting subject. Still, they have left us with some questions. First, since it is known that a combination of clinical and biochemical parameters increases the probability of CBD stones up to $>90 \%$ [3], we wonder if it was specifically asked whether there were any signs of CBD obstruction (jaundice, light faeces, dark urine)? Second, since more than $7 \%$ of the patients did not undergo ultrasonography: was this not the first diagnostic imaging technique in the authors' clinic in all cases, or were some patients asymptomatic? Third, for reasons of costs and radiation safety: why was the number of computed tomography (CT) scans so enormously high (almost one in every four patients)? This is especially interesting as the authors themselves state that this diagnostic tool is usually not recommended as the diagnostic modality of choice to predict absence or presence of CBD stones [1]. Finally, did the authors test the combination of more than twofold elevated total bilirubin and alkaline phosphatase as a predictor for CBD stones, which works well in our experience?

\section{References}

1. Yang M-H, Chen T-H, Wang S-E et al (2008) Biochemical predictors for absence of common bile duct stones in patients undergoing laparoscopic cholecystectomy. Surg Endosc 22:16201624

2. van de Hul RL, Plaisier PW, Hamming JF, Bruining HA, van Blankenstein M (1993) Detection and management of common bile duct stones in the era of laparoscopic cholecystectomy. Scand J Gastroenterol 28:929-933

3. Lacaine F, Corlette MB, Bismuth H (1980) Preoperative evaluation of the risk of common bile duct stones. Arch Surg 115:1114 1116
P. W. Plaisier $(\bowtie)$

Department of Surgery, Albert Schweitzer Hospital, PO Box 444, 3300 AK Dordrecht, The Netherlands e-mail: p.w.plaisier@asz.nl

R. L. van der Hul

Department of Surgery, Van Weel Bethesda Hospital, PO Box 153, 3247 BW Dirksland, The Netherlands 